\title{
Steady-state CFD modelling and experimental analysis of the local microclimate in Dubai (UAE)
}

\author{
Syeda Firdaus Fatima and Hassam Nasarullah Chaudhry* \\ School of Energy, Geoscience, Infrastructure and Society, Heriot-Watt University, P.O. Box 294 345, Dubai, \\ United Arab Emirates
}

Received: 17 March 2016 / Accepted: 14 February 2017

\begin{abstract}
Rapid urban growth and development over the past few years in Dubai has increased the rate at which the mean maximum temperatures are rising. Progressive soaring temperatures have greater effect of heat islands that add on to the high cooling demands. This work numerically explicated the effect of HIs in a tropical desert climate by adopting Heriot-Watt University Dubai Campus (HWUDC) as a case study. The study analysed thermal flow behaviour around the campus by using Computational Fluid Dynamics (CFD) as a numerical tool. The three dimensional Reynolds-Averaged Navier-Stokes (RANS) equations were solved under FLUENT commercial code to simulate temperature and wind flow parameters at each discretised locations. Field measurements were carried out to validate the results produced by CFD for closer approximation in the representation of the actual phenomenon. Results established that the air temperature is inversely proportional to wind velocity. Hotspots were formed in the zone 1 and 3 region with a temperature rise of $9.1 \%$ that caused a temperature increase of $2.7^{\circ} \mathrm{C}$. Observations illustrated that the building configuration altered the wind flow pattern where the wind velocity was higher in the zone 2 region. Findings determined increase in the sensible cooling load by $19.61 \%$ due to $1.22^{\circ} \mathrm{C}$ temperature rise. This paper highlighted the application of CFD in modelling an urban micro-climate and also shed light into future research development to quantify the HIs.
\end{abstract}

Keywords: CFD / urban heat island / hotspots / thermal flow / sensible load

\section{Introduction}

Over the last few years, the world has been rapidly developing towards urbanisation that is negatively affecting the environment leading to a substantial increase in the cooling requirements. One of the consequences of this phenomenon is the heat island effect. The increase in the surface temperature of urban structures leads to alteration of urban microclimate as a result of variations in convective heat exchanges from these surfaces [1]. This leads to an increase in the air temperature, where metropolitan cities with hard built-up structures have higher mean air temperatures than the immediate rural areas surrounding it.

Oke [2] portrayed the heat island phenomenon as the heat being trapped within the densely built up urban areas leading to elevated ambient air temperatures in the centre of the city as compared to the surrounding outlying areas. Tam et al. [3] mentioned it as an anthropogenic phenomenon due to modifications of the urban surfaces by human

\footnotetext{
* e-mail: H.N.Chaudhry@hw.ac.uk
}

inhabitation that leads to a higher air temperature in a dense urban centre. The elevated temperatures due to this phenomenon lead to higher energy demand for cooling, increased concentration of air pollutions and greenhouse gases and reduced thermal comfort.

Meteorological conditions such as wind speed and direction is one of the major factors affecting the intensity of heat islands within the built environment [4]. High wind velocity allows for a reduction in the phenomenon whereas stagnant conditions increase it, where the wind flow pattern and velocity is influenced by the urban configuration that in turn affects the intensity of the heat exchange [5]. Allegrini et al. [6] observed increase in the convective heat transfer with the building façade and heat removal due to increased flow of wind within the street canyon. Brown [7] indicated that the temperature build-up varies according to the wind velocity, where the intensity is significant during calm wind conditions and is low under strong wind conditions. Fisher et al. [8] classified calm air as when the wind velocity is less than $3 \mathrm{~m} / \mathrm{s}$. As the wind speed exceeds $3 \mathrm{~m} / \mathrm{s}$ it drifts out the warm air from the city lowering the intensity of the heat island phenomenon. 
This study carries out a steady state temperature assessment in context of wind flow pattern, micro-climatic speed, building geometry and urban surface temperature using the Heriot-Watt University Dubai Campus (HWUDC) as the case study. The thermal and aerodynamic parameters impacting heat islands were numerically simulated using Computational Fluid Dynamics, the results of which were validated through physical field measurements. Specific hotspot locations around the building infrastructure were determined in response to the external local climate to quantify the cooling loads due to sensible conductive heat gains through external.

\section{Previous related work}

Previous studies [9-12] have reviewed the influence of steady state surface temperatures and heat islands as a function of urban geometry/orientation, nature of urban surfaces, meteorological conditions, air movement and air velocity. The intensity of the heat island effect can be mitigated by modifying these parameters strategically. The assessment methodologies implemented in literature provides a fundamental basis in the approach of assessing the temperature profile and cooling loads on the built environment located in hot arid climates. A study conducted by Radhi [13] has shown that the thermal environments are influenced by built environment and temperature increase could be well within $2-4^{\circ} \mathrm{C}$. The use of numerical tools such as CFD in predicting both steady and dynamic thermal and flow distribution around buildings has also been extensively investigated in previous literature $[14-16]$ as described in the following sections.

\subsection{Impact, causes and mitigation strategies of steady state heat islands}

Abid et al. [9] investigated the effect of solar radiation and pollution dispersion of the urban microclimate in Masdar City, Abu Dhabi at three times of the day. CFD simulations were carried out in ANSYS FLUENT using $k-\varepsilon$ model with steady Navier-Stokes equations. Results from the simulation depict higher air temperatures on the windows facing the sun. It was found that increase in the ambient air temperature was due to higher surface temperatures of ground and roof, heated up through solar radiation. The work concluded that higher aspect ratio prevents direct solar radiation heating up urban surfaces and reducing negative effects on the urban micro-climate.

Cho et al. [10] analysed the thermal environment on a large-scale basis of a surrounding area $\left(5 \mathrm{~km}^{2}\right.$ and $\left.10 \mathrm{~km}^{2}\right)$ of Tokyo's waterfront bay to examine the heat island phenomenon. CFD simulations were performed using $k-\varepsilon$ turbulence model and were validated against the observational measurements. Results depicted that the air temperature at $2 \mathrm{~m}$ from ground was dropped by $1^{\circ} \mathrm{C}$ to $2{ }^{\circ} \mathrm{C}$ above large vegetative areas and rivers. The study highlighted that the upward momentum (buoyancy driven) of air velocity occurs in the region of higher air temperature. The research work concluded that the existence of upward and downward momentum pairs of air velocity influences the variation in ambient air temperature.
Taleb and Abu-Hijleh [11] studied the impacts of various urban configurations in Dubai on temperature variations. 27 simulations were carried out with different combinations of urban layout, wind speed $(0.1 \mathrm{~m} / \mathrm{s}$ for no wind case scenario, $3.6 \mathrm{~m} / \mathrm{s}$ as preliminary wind speed and $7 \mathrm{~m} / \mathrm{s}$ for summer only to comprehend the influence of increasing wind speed on temperature variation) and time of the year (June, December and September) with fixed initial temperature input of $32^{\circ} \mathrm{C}$. Results revealed that the Bastakiya configuration (Fig. 1) had lower temperatures in the summer case. On comparison of results with presence and absence of wind, there was a reduction in temperature fluctuations in the presence of wind leading to a reduction in the existence of hot spots. The study concluded that the Bastakiya configuration is the best in thermal performance under all conditions in terms of the location of site and alliance of prevailing winds parallel to road.

Priyadarshini et al. [12] highlighted the fundamental factors causing the heat island phenomenon in Singapore. The CFD simulations used $k-\varepsilon$ turbulence model equation under finite volume technique. The boundary conditions were acquired from meteorological weather data and field measurements. The experiment was validated through physical field measurements. It was found that the temperature dropped by $0.7^{\circ} \mathrm{C}$ with an increase in corresponding air velocity by $35 \%$ due to the presence of high rise towers of optimum $\mathrm{H} / \mathrm{W}$ ratio. The study concluded that by strategically locating the high rise towers of optimum $\mathrm{H} / \mathrm{W}$ ratio, air flow can be enhanced within street canyons thereby reducing the intensity of the heat island.

\subsection{Application of CFD in the assessment of thermal and flow profiles}

Allegrini et al. [6] investigated the influence of urban microclimate on building energy demands of an urban neighbourhood. The computational domain comprised of a total of 14 buildings arranged in varying aspect ratios, simulated using 3-D Reynolds-Averaged Navier-Stokes (RANS) equations and $k-\varepsilon$ turbulence model within the OpenFOAM numerical code. A total of four different weather conditions were modelled with wind speeds ranging from $0.3 \mathrm{~m} / \mathrm{s}$ to $4.7 \mathrm{~m} / \mathrm{s}$. The findings determined that the difference in air temperature concerning the approach flow and the air inside an urban canyon or the local heat island intensities can be as high as $2.5^{\circ} \mathrm{C}$ causing a significant increase in cooling demands. The study concluded that the CFD approach is a useful tool for predicting heat island intensities for urban areas.

Toparlar et al. [14] presented an analysis of urban microclimate in the city of Rotterdam, Bergpolder Zuid by conducting CFD simulations using 3D unsteady RANS equation under $k-\varepsilon$ turbulence model on a high resolution grid. Results depict that under calm wind conditions, the surface temperatures of urban elements were relatively high. Streets perpendicular to the wind velocity had reduced ventilative cooling effect. CFD produced similar urban surface temperature in comparison to the satellite thermal 

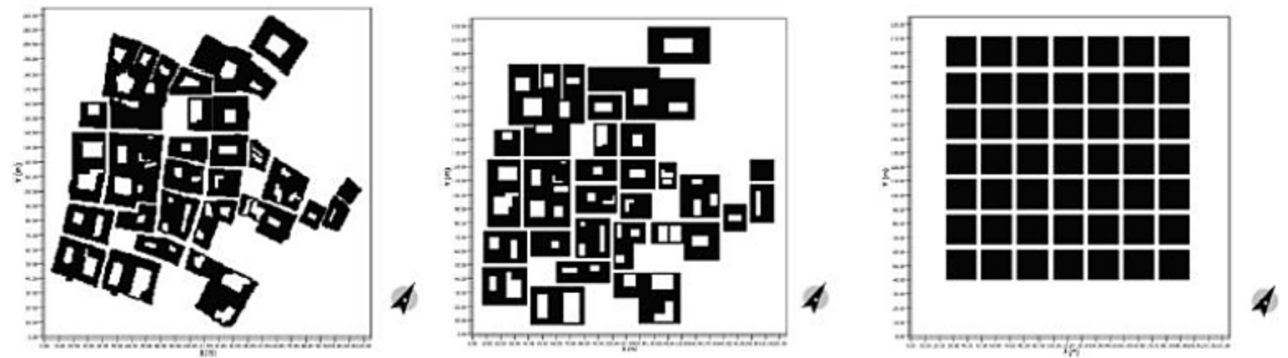

Fig. 1. Bastakiya (left), orthogonal (centre), volume ortho (right) modelled in ENVI-met [11].

images with a $7.9 \%$ deviation. The study concluded that CFD can be used as a numerical tool to assess urban microclimate and identify problematic areas.

Song and Liu [15] evaluated the distribution of thermal humidity and velocity towards the urban micro-climate in the presence of solar radiation and humidity transportation. The boundary conditions were set from the data obtained through meteorological centre. Standard $k-\varepsilon$ turbulence equation was used as turbulence model. Results illustrate that the building configuration significantly modified the air temperature and moisture content. With increase in building height the cooling effect of the water feature was reduced due to reduced exposure to the sun blocked by tall buildings. The investigation highlighted that the CFD simulations can be used as an effective tool to predict thermal environment of an urban micro-climate.

Setaijh et al. [28] applied ANSYS FLUENT on a case study in the city of Madinah, Saudi Arabia to analyse the thermal comfort in the urban streets. The simulation used RANS turbulence equation with $k-\varepsilon$ model and standard wall function. Results from the simulation were compared against the field measurements, where the air velocity obtained from the simulation was $6.5 \mathrm{~m} / \mathrm{s}$ and $7 \mathrm{~m} / \mathrm{s}$ from the field measurements indicating less than $20 \%$ error. The study stated that according to Wilkinson et al. [17], acceptable error for CFD results is up to $20 \%$ thus validating the simulation performed. Results depict an acceleration in wind velocity by $1.3 \mathrm{~m} / \mathrm{s}$ with taller buildings enhancing wind movement along the streets also causing a reduction in the air temperature by $2{ }^{\circ} \mathrm{C}$. The study concluded that the urban geometry and orientation influences the air velocity and temperature affecting the thermal comfort along the streets. The study also suggested that CFD can be used to evaluate complex micro-climatic issues such as thermal comfort, pollution diffusion, quality of air and wind flow patterns along with the effects of vegetation and relative humidity.

Previous investigations have reviewed the effects of a steady increase in built environment temperature on a large scale basis where the intensities were quantified based on the temperatures occurring in the rural and urban areas. The studies revolved around mitigation strategies and how different configurations of wind directions would affect the heat island phenomenon. However, a numerical and farfield assessment of the temperature build up on buildings in UAE's hot arid climates has not been extensively covered in the literature. Therefore, this work assessed the thermal and flow parameters around the HWUDC to comprehend the behaviour of rising temperatures locally in order to mitigate the phenomenon in the most effective way in future works.

\section{Physical domain}

The Heriot-Watt University Dubai Campus was selected as the case study to critically analyse the occurrence of thermal and flow parameters. The campus comprises of Phase 1 and Phase 2 buildings with an overall area of $28000 \mathrm{~m}^{2}$ located in the Dubai International Academic City. The building has a symmetrical geometry with flushed and recessed exterior walls in a uniform fashion. Phase 1 of the building measures $51 \mathrm{~m}$ wide, spreading across a length of $132 \mathrm{~m}$ reaching $20 \mathrm{~m}$ in height. Phase 2 of the building comprises of three blocks consisting of five floors with length, width and height of $32 \mathrm{~m}, 12 \mathrm{~m}, 16 \mathrm{~m}$ respectively. One block for auditorium with dimensions as $25 \mathrm{~m} \times 35 \mathrm{~m} \times 5 \mathrm{~m}$. The two phases are situated at a distance of $15 \mathrm{~m}$ measured from the central auditorium block. Figure 2 displays the HWUDC modelled in threedimension on a scale of $1: 100$.

The window to wall ratio (WWR) on the geometry was $37 \%$. Glazing areas with high WWR were mainly considered to cause significant temperature increase for simplification purposes. In order to set the inlet boundary conditions an enclosure of $212 \times 152 \times 40 \mathrm{~m}$ was created around the geometry such that it was 2.5 times the length of the physical domain in $\mathrm{x}, \mathrm{y}$ and $\mathrm{z}$ direction to avoid rebound effect.

The study assessed the heat exchange activity amidst the two building phases (transitional circulation space) that has relatively high level of pedestrian movement. The resultant high temperatures due to the phenomenon would lead to increase in the thermal discomfort thus identification of activity in this area was considered to be crucial. The building had been divided into three zones for illustration purposes as displayed in Figure 3.

\subsection{Experimental setup}

Field measurements were conducted around the HWUDC required for the inlet boundary conditions and experimental validation to illustrate a closer representation of the real case scenario. The measurements were logged on 2nd February 2015 at 16:00. As the wind was prevailing from the northwest (NW) direction, velocity and temperature 
(a)

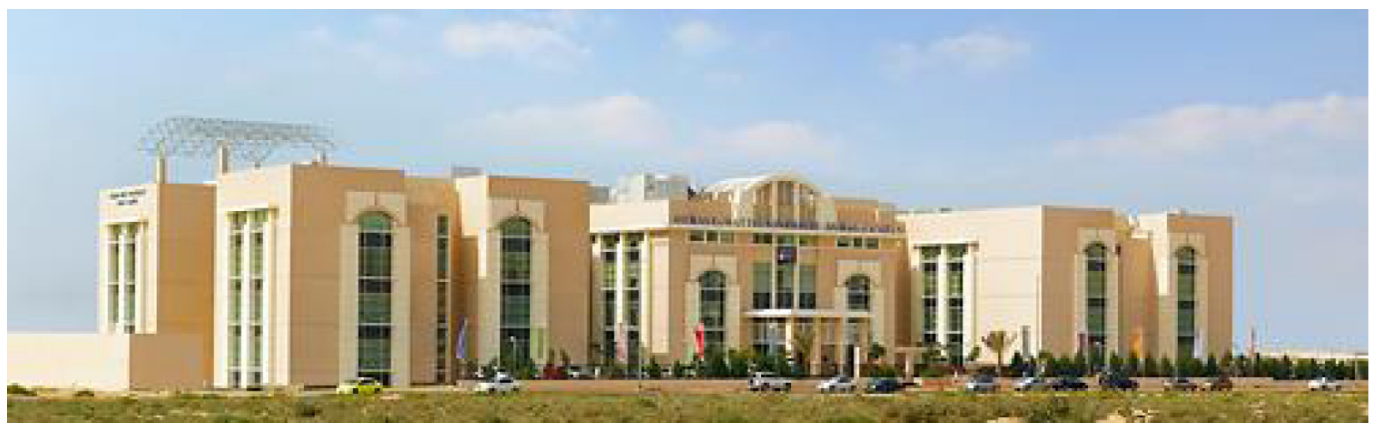

(b)

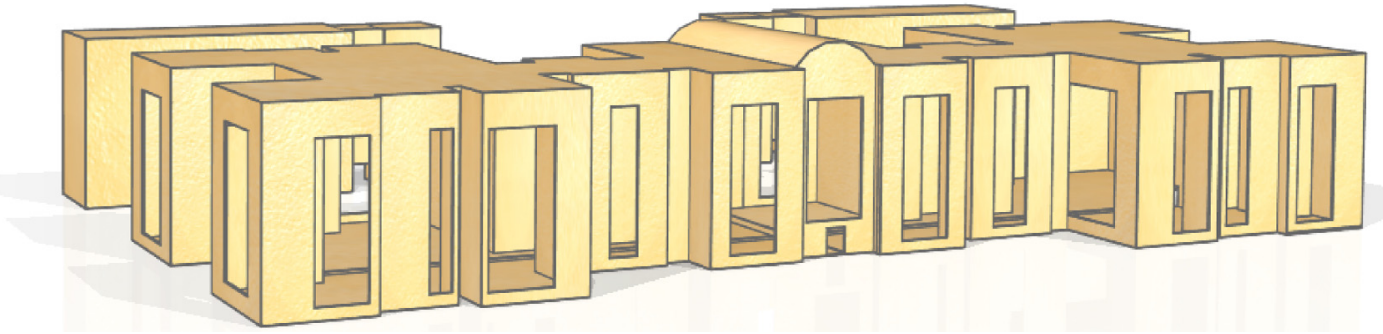

Fig. 2. (a) Heriot-Watt University Dubai Campus, (b) modelled version.

(b)

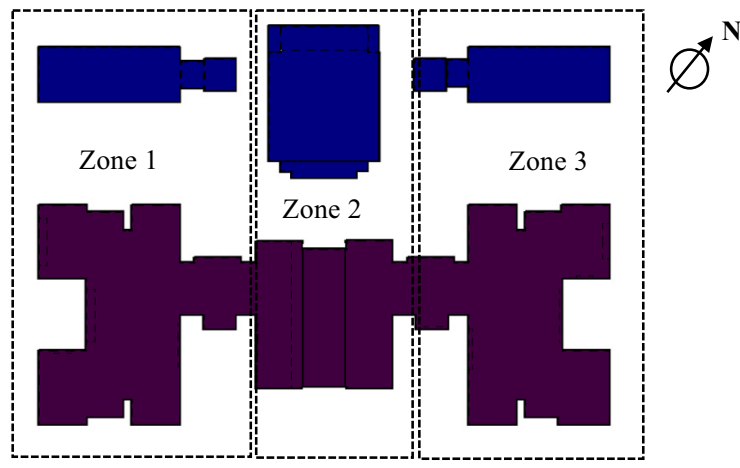

Phase 1 Phase 2
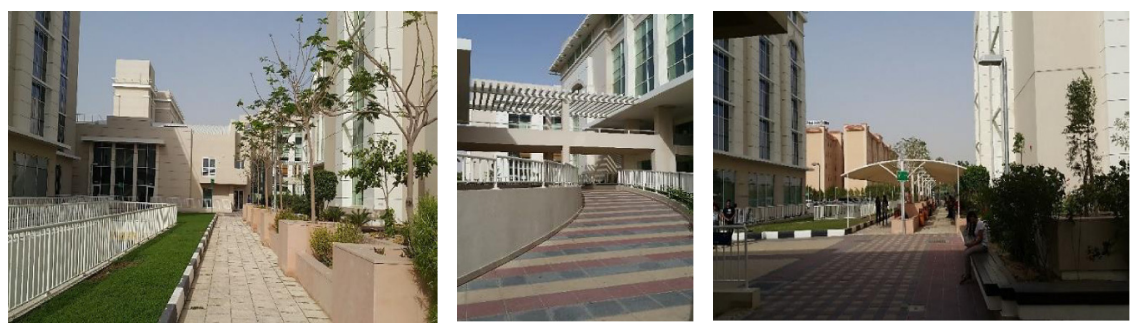

Fig. 3. (a) Division of zones and phases of modelled HWUDC plan, (b) three created zones as seen from north direction.

parameters were set at the NW side of the symmetry enclosure as the inlet boundary conditions. In order to assess the effect of high temperature of the campus façade, surface temperature of the glazing and external wall were also input as the boundary conditions. Extech heat stress meter (HT30) having an accuracy of $\pm 1 \%$ with a $0.1{ }^{\circ} \mathrm{C}$ resolution was used to record the dry-bulb temperature. The Meterman IR 608 infrared thermometer of $\pm 2 \%$ accuracy rating having a resolution of $0.2^{\circ} \mathrm{C}$ and hot wire anemometer (C.A 1226 Thermo-Anemo F) having $\pm 3 \%$ accuracy with a $0.01 \mathrm{~m} / \mathrm{s}$ resolution were used to record the surface temperature of the façade and air velocity respectively. 


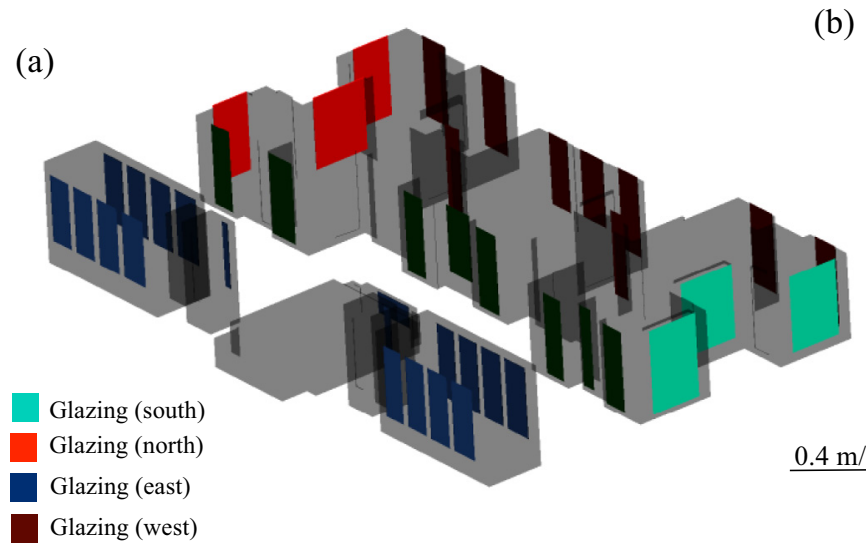

(b)

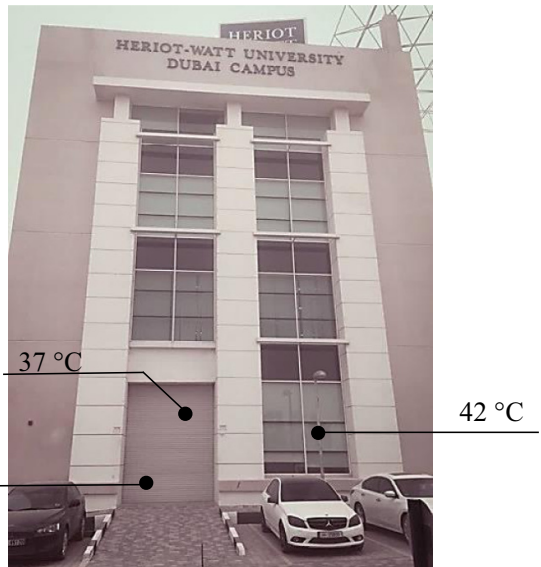

Fig. 4. (a) Glazing boundary conditions, (b) surface temperature, ambient temperature and velocity measured on the south facing side for inlet boundary conditions.

Figure 4a displays the boundary conditions that were specified on the glazing of the buildings. Windows facing south were grouped together and set at a surface temperature of $42^{\circ} \mathrm{C}$ obtained from the field measurements. Figure $4 \mathrm{~b}$ displays the real image of inlet condition location.

In order to validate the results generated from the CFD model, 10 discrete measurement points were created along the circulation zone connecting the two phases across the three zones. Figure 5 displays the points at which the investigated parameters were measured. The dry bulb temperature and air velocity recorded at the designated points were used as the measurement parameters to validate the CFD findings.

\subsection{Data reduction}

Readings obtained from the physical field measurements were applied to calculate the sensible heat gain due to conductive heat transfer through glazing in order to analyse the impact on the cooling load of the building. Heat transfer coefficient for double glazed glass of the building was taken to be as $2.26 \mathrm{~W} / \mathrm{m}^{2} \mathrm{~K}$ [18]. Surface area of the glazed area was estimated as $87.31 \mathrm{~m}^{2}$. Temperature difference could be acquired through measured data or computational results. These variables were merged to obtain the degree of convective heat transfer due to glazing in equation (1).

$$
Q_{\text {glazing }}=U A(\Delta T)
$$

where $Q_{\text {glazing }}$ represents sensible load due to convective heat exchanges through glazing $(\mathrm{W}), U$ represents the thermal transmittance of the glazing $\left(\mathrm{W} / \mathrm{m}^{2} \mathrm{~K}\right), A$ denotes the surface area of the external glazing $\left(\mathrm{m}^{2}\right)$ and $\Delta T$ represents the temperature difference between the outdoor and indoor environment in ${ }^{\circ} \mathrm{C}$.

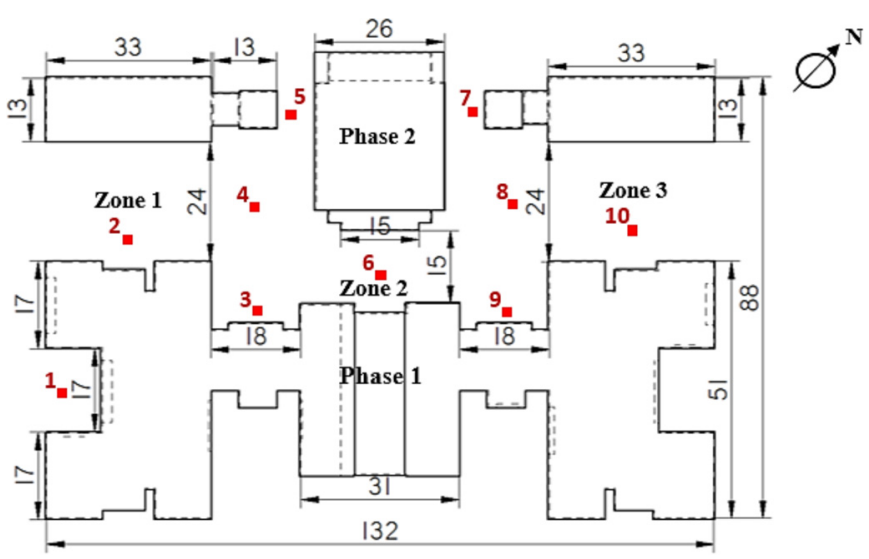

Fig. 5. Points indicating physical field measurements conducted in HWUDC (dimensions in meters).

\section{Computational domain}

\subsection{Solution methods}

According to Chaudhry [16] the three-dimensional Reynolds-Averaged Navier-Stokes (RANS) using the $k-\varepsilon$ turbulence model is one of the most suitable numerical methods for built environment simulations. The model solves for two governing equations, the kinetic energy and turbulent dissipation. Abid et al. [9] used RANS along with the turbulent kinetic energy model to simulate the effect of solar radiation in an urban microclimate. Priyadarshini et al. [12] applied $k-\varepsilon$ turbulence model to simulate heat island phenomenon in Singapore. Furthermore, Allegrini et al. [6], Song and Liu [15], Toparlar et al. [14], etc., have applied the same to analyse and simulate the urban thermal environments as reviewed in Section 2.2. Thus the current research study used 3D steady state Reynolds- 


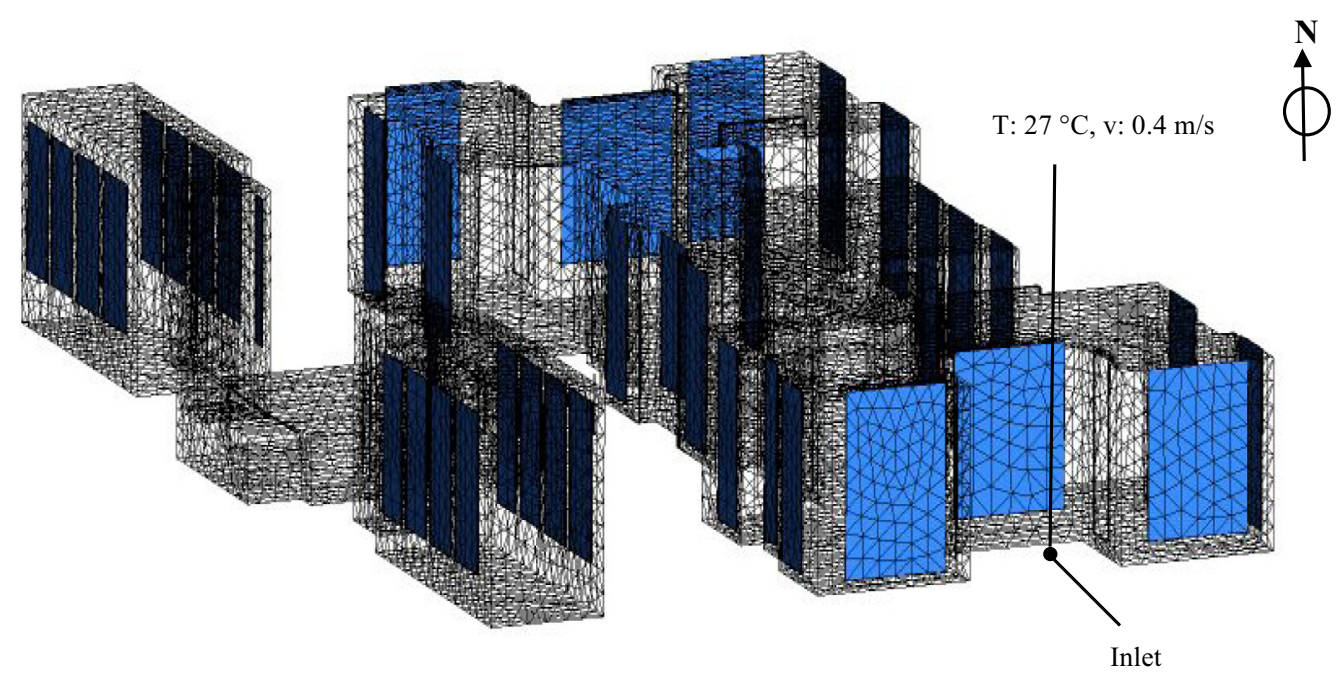

Fig. 6. Representation of the flow domain.

Averaged Navier-Stokes (RANS) equation using the $k-\varepsilon$ turbulence model to resolve the discretised computational domain.

Therefore, the RANS equations along with the momentum and continuity equations were solved using the commercial CFD code for the velocity and pressure field simulations. The model employs the control-volume technique and the Semi-Implicit Method for PressureLinked Equations (SIMPLE) velocity-pressure coupling algorithm with the second order upwind discretisation. The turbulence kinetic energy, $k$, and its rate of dissipation, $e$, are obtained from the following transport equations formulated in equations (2) and (3).

$$
\begin{aligned}
\frac{\partial}{\partial t}(\rho k)+\frac{\partial}{\partial x_{i}}\left(\rho k u_{i}\right) & =\frac{\partial}{\partial x_{j}}\left[\left(\mu+\frac{\mu_{t}}{\sigma_{k}}\right) \frac{\partial k}{\partial x_{j}}\right]+G_{k} \\
& +G_{b}-\rho \varepsilon-Y_{M}+S_{k}, \\
\frac{\partial}{\partial t}(\rho e)+\frac{\partial}{\partial x_{i}}\left(\rho e u_{i}\right) & =\frac{\partial}{\partial x_{j}}\left[\left(\mu+\frac{\mu_{t}}{\sigma_{e}}\right) \frac{\partial e}{\partial x_{j}}\right] \\
& +C_{1 e} \frac{e}{k}\left(G_{k}+C_{3 e} G_{b}\right)-C_{2 \varepsilon} \rho \frac{e^{2}}{k} \\
& +S_{e},
\end{aligned}
$$

where $G_{k}$ represents the generation of turbulence kinetic energy due to the mean velocity gradients, $G_{b}$ represents the generation of turbulence kinetic energy due to buoyancy. $Y_{M}$ represents the contribution of fluctuating dilatation in compressible turbulence to the overall dissipation rate. $C_{1 e}, C_{2 e}$ and $C_{3 e}$ are constants; $\sigma_{k}$ and $\sigma_{e}$ are the turbulent Prandtl numbers for $k$ and $e$.

\subsection{Mesh generation}

Previous studies by Shengwei [19], Dandgawal [20], Houdal et al. [21] have indicated that a tetrahedral mesh is able to compute the numerical solutions with acceptable accuracy in relatively low cost and computational time. An unstructured tetrahedral mesh was therefore applied due its complex geometrical configuration having series of flushed and recessed exterior walls. The relevance centre of the unstructured mesh was set to 'fine' with 'high' smoothing sizing in order to resolve the flow fields and temperature fluxes around the corners of the recessed and flushed walls. The meshed model comprised of 113040 nodes and 580464 elements to compute the numerical codes of the physical domain. Figure 6 displays the meshed model with the inlet conditions.

\subsection{Boundary conditions}

The applied boundary conditions (Tab. 1) comprised of an inlet velocity of $0.4 \mathrm{~m} / \mathrm{s}$ approaching from the north-west direction. The geometry was modelled as a solid zone while the enclosure was modelled as a fluid zone for the analyses. The boundary conditions were kept identical throughout the numerical investigation for all analysed models.

\section{Results and analysis}

\subsection{Model validation}

The validation of the results is considered to be of utmost importance as the computational programme can have numerous sources of error that could fail to represent any major or critical parameters and behaviour in the real case scenario. Uncertainty in modelling errors due to approximations and assumptions in the physical geometry, mathematical equations, boundary conditions and numerical errors such as inappropriate grid discretisation and improper grid convergence may lead to inaccurate results. Thus validation of the simulated results against physical field results is scientifically significant.

As observed from Figure 7, the error percentage for the temperature variable ranged from $2 \%$ to $17 \%$ with an average error of $11 \%$ whereas the velocity parameter incorporated a mean variation in the range of $19 \%$. The error bars are plotted at $5 \%$ for the CFD recordings. 
Table 1. Boundary conditions.

\begin{tabular}{ll}
\hline Parameter & Value \\
\hline Inlet velocity & $0.4 \mathrm{~m} / \mathrm{s}$ \\
Inlet temperature & $27^{\circ} \mathrm{C}$ \\
Wall temperature & $37^{\circ} \mathrm{C}$ \\
Glazing (east) & $25^{\circ} \mathrm{C}$ \\
Glazing (north) & $26^{\circ} \mathrm{C}$ \\
Glazing (south) & $42^{\circ} \mathrm{C}$ \\
Glazing (west) & $30^{\circ} \mathrm{C}$ \\
Geometry & Solid zone \\
Enclosure & Fluid zone \\
Operating pressure & Atmospheric \\
Viscous model & $k-\varepsilon$ Eq. (2)) \\
Near-wall treatment & Standard wall functions \\
Velocity formulation & Absolute \\
\hline
\end{tabular}

According to Wilkinson et al. [17], an acceptable error for CFD results is up to $20 \%$. Thus it can be established that the numerical model has been validated.

\subsection{Flow and thermal profiles}

Figure 8 displays the temperatures distribution in the direction of the inlet conditions attaining an ambient temperature of $27^{\circ} \mathrm{C}$. Higher temperatures were observed around the immediate adjacent areas of the glazed façade. A section of zone 1 located in between the flushed and recessed geometry of the phase 1 building as illustrated revealed relatively warmer surface temperature (hotspot) leading to probable higher heat exchange intensity in that area. Lower surface temperature was observed in zone 2 although higher convective heat fluxes that generally occur with any glazing façade of a building would lead to rise in the temperatures. The highest overall surface temperature that distributed across a relatively larger area was found to be in zone 3 .

Figure 9 shows the velocity levels of the flow field stirring around the 3 zones of the campus. With an inlet velocity of $0.4 \mathrm{~m} / \mathrm{s}$, the contour levels in zone 1 depicts that the zone experienced highest air velocity in that region of up to $0.64 \mathrm{~m} / \mathrm{s}$. Following the contact between the building and the approaching wind flow, the speed adjacent to the buildings reduced considerably. The flow profile around the recessed geometry displayed a significant decrease in the wind speed that can almost be considered as stagnant wind conditions. However, the outdoor corridor between phase 1 and phase 2 of the building had accelerated wind flow as compared to the flow in between the building geometry. The approaching wind from zone 1 funnelled in to the narrow corridor of zone 2 . Furthermore, zone 3 experienced relatively higher air velocity than zone 2 section due to a higher re-circulation of air in proportion to the zonal area.

The temperature variation between the structural configuration of the buildings and the surrounding micro-climate is displayed in Figure 10. A temperature (a)

$\square$ Texp $\left({ }^{\circ} \mathrm{C}\right) \quad \square$ Tansys $\left({ }^{\circ} \mathrm{C}\right)$

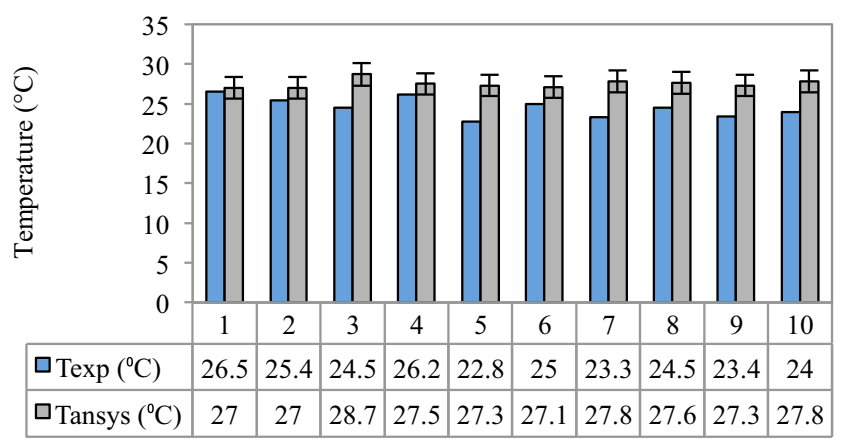

(b)

$\square \operatorname{Vexp}(\mathrm{m} / \mathrm{s}) \quad \square \operatorname{Vansys}(\mathrm{m} / \mathrm{s})$

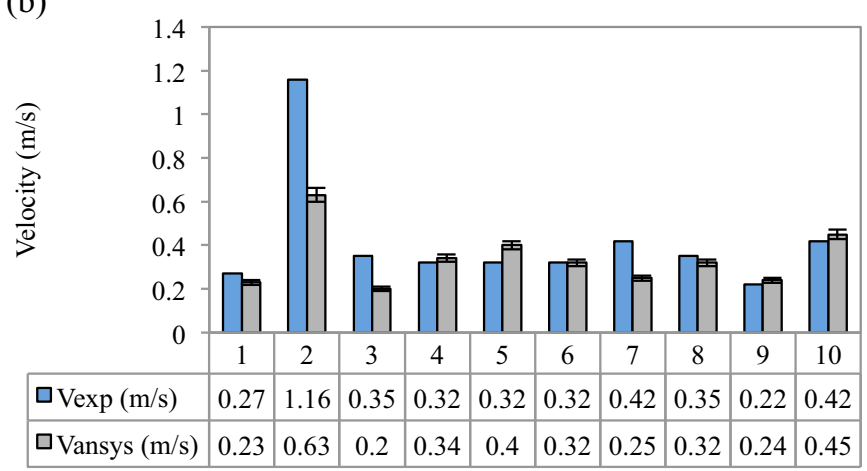

Fig. 7. Comparison between CFD and experimental results for (a) temperature and (b) velocity.

increase of $28 \%$ was observed on the external walls and glazing indicated by the increased surface temperature. A temperature increase of $7 \%$ was observed at the immediate surrounding areas to both building phases highlighting the effect locally formed of heat islands.

In order to assess the findings quantitatively, a line was created intersecting through the three zones at a height of $2 \mathrm{~m}$ above ground level to simulate the conditions experienced by the pedestrians. Figure 11a displays the temperature formation across the building geometry. As observes, the temperature reached its highest peak in the region of zone 3 with a value of $28.62^{\circ} \mathrm{C}$. This trend was contrary to the air velocity Figure $11 \mathrm{~b}$ which indicated a reduction to approximately stagnant conditions, thus confirming the inverse proportionality between the two parameters.

Two perpendicular lines (lines 3 and 4) in zone 1 and 3 were plotted on a temperature graph connecting the two phases of the building. Figure 12a illustrated that line 4 in the zone 3 region had the highest maximum temperature of $33.8^{\circ} \mathrm{C}$ on the glazing as compared to line 3 in zone 1 . The overall trend of the graph also depicted that zone 3 had higher temperature intensity than zone 1 . Furthermore the temperature tends to rise in region close to the building façade and roughly remained constant in the central region of the lines in both the zones. Lowest temperatures were 


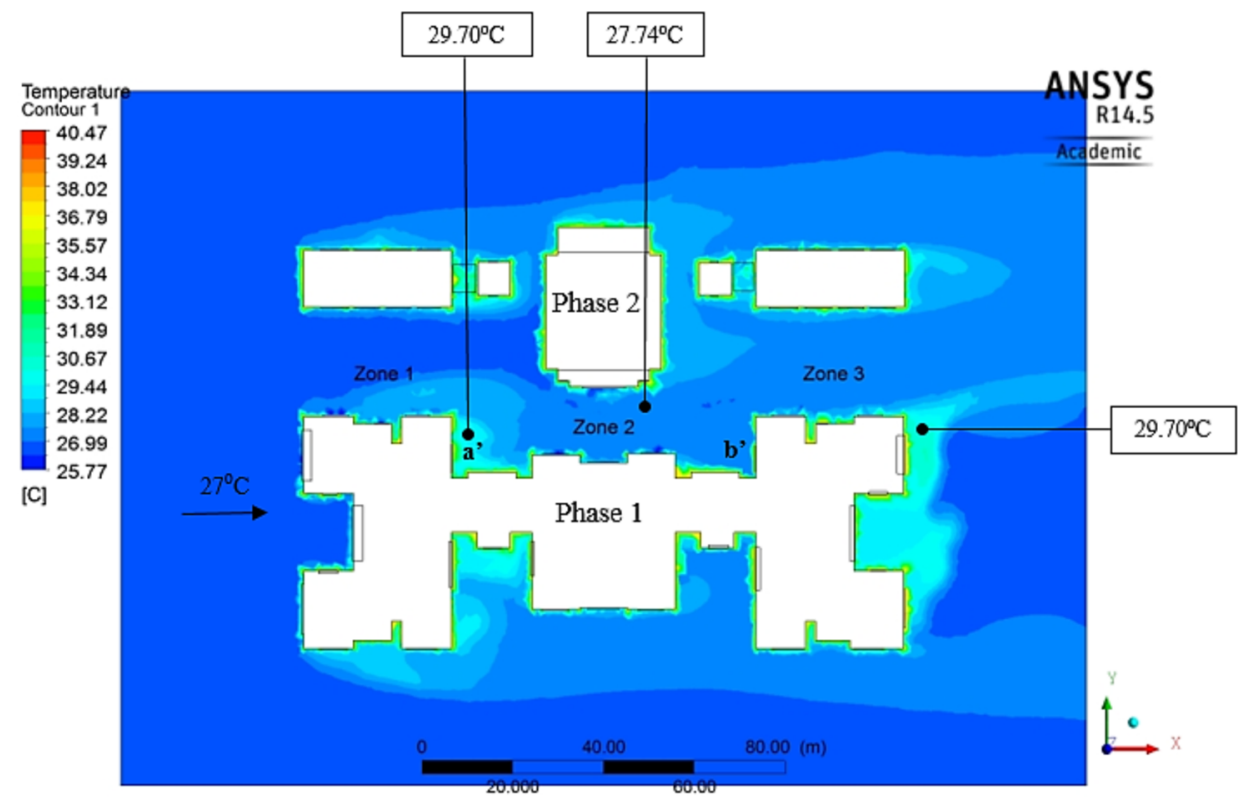

Fig. 8. Surface temperature in XY plane at $2 \mathrm{~m}$ above ground level.

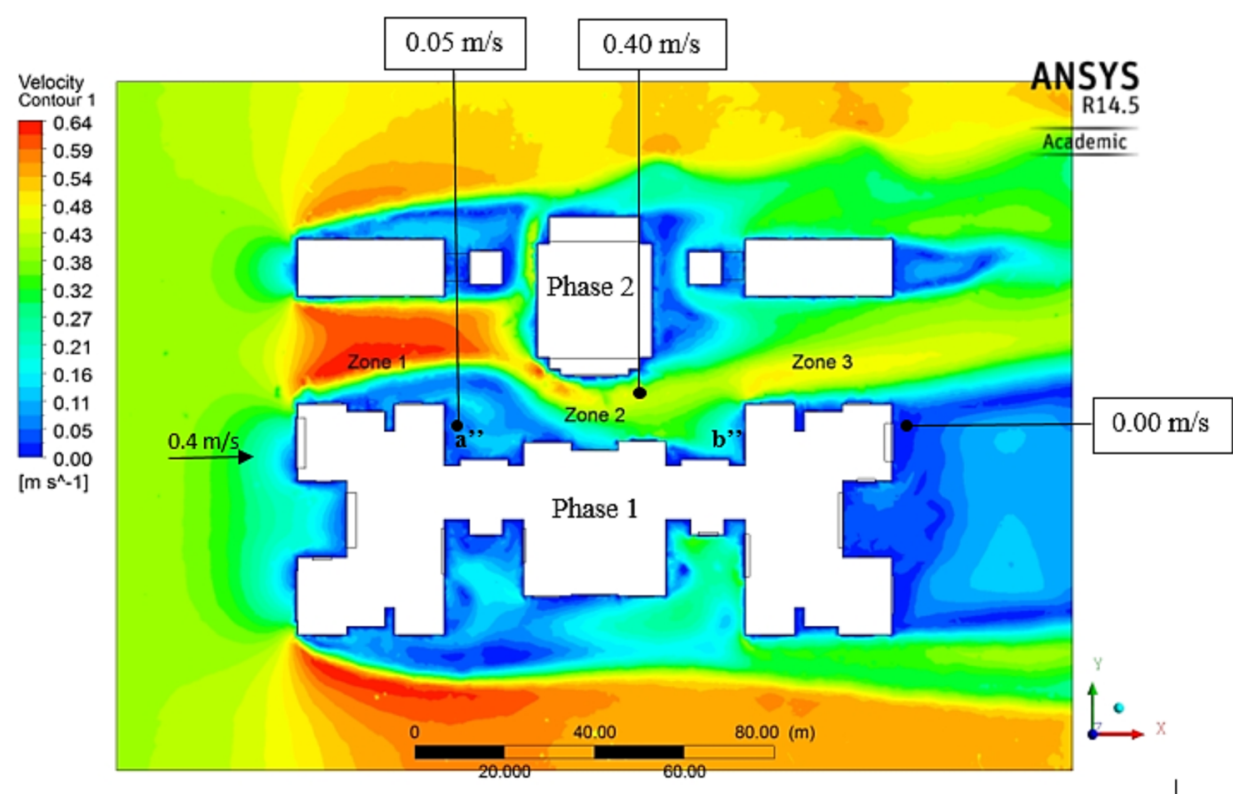

Fig. 9. Velocity distribution in XY plane at $2 \mathrm{~m}$ above ground level.

recorded in these central regions of line 3 and 4 as $26.8^{\circ} \mathrm{C}$ and $27.1^{\circ} \mathrm{C}$ respectively with zone 1 having the lowest minimum temperature.

Figure $12 \mathrm{~b}$ shows a lower air velocity near phase 1 building than phase 2 (zone 1). Maximum air velocity of $0.17 \mathrm{~m} / \mathrm{s}$ was found to be at line 4 which falls under zone 3 close to the phase 2 building. However, the overall air velocity was higher at line 3 in the zone 1 region. The least minimum velocity was found at the phase 1 side of zone 3 at $0.005 \mathrm{~m} / \mathrm{s}$ which can almost be considered as stagnant wind condition.

\subsection{Sensible cooling loads}

Probe points were plotted on all areas adjacent to windows within the outdoor corridor in the ANSYS results interface and were calculated using the average function calculator within the software. Conductive heat gain due to glazing with maximum detected temperature $\left(28.22^{\circ} \mathrm{C}\right)$ was calculated to find the possible contribution of sensible heat gain on the cooling load of the building as a worst case scenario. Figure 13 shows the graphical representation of the increase in cooling loads before and after the steadystate heat island effect. A $1.22{ }^{\circ} \mathrm{C}$ increase in the ambient 


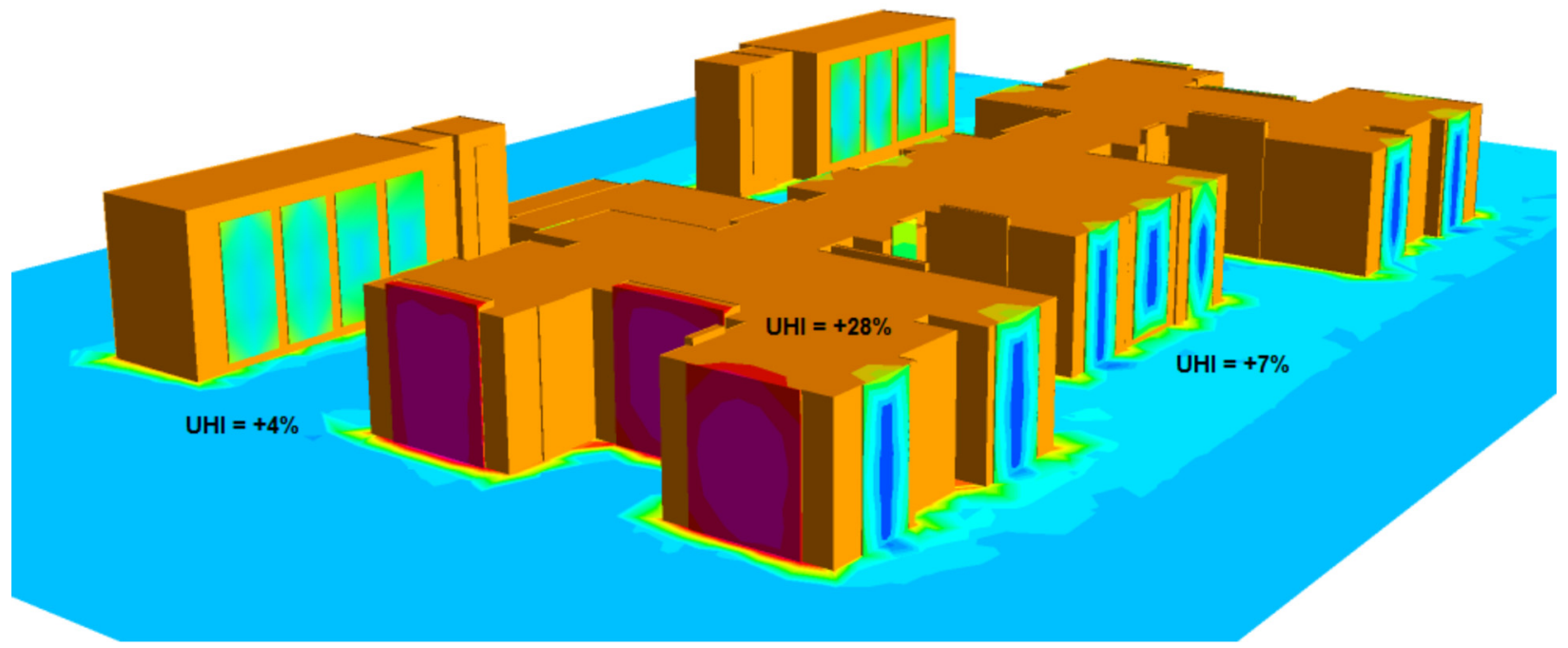

Fig. 10. Representation of the local temperature formations on the building geometry and the surrounding environment.

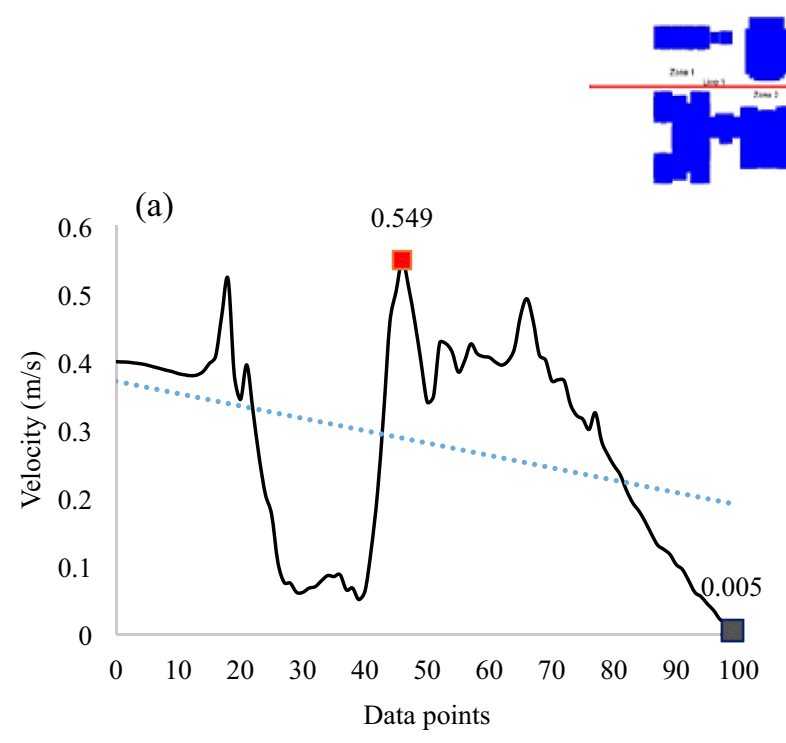

a Max $\quad$ Min $\cdots \cdots$ Linear (velocity trend $(\mathrm{m} / \mathrm{s}))$

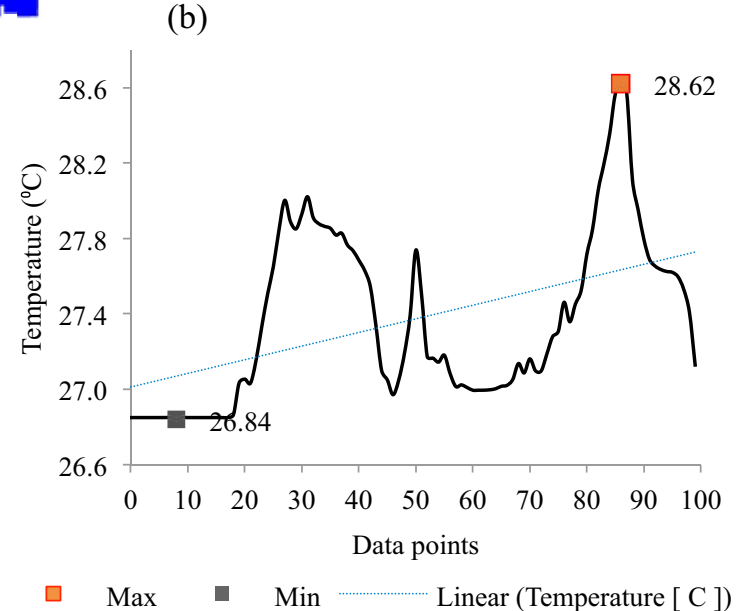

Fig. 11. Instantaneous variations in axial (a) temperature, (b) velocity parameters.

air temperature adjacent to the glazing caused the conductive heat gain through glazing to increase by $19.61 \%$. This is further discussed in Section 6.3.

\section{Discussions}

\subsection{Hotspot existence and relationship between temperature \& air velocity}

The most common trend that could be analysed from the results was the increase in local temperature in areas with low wind speed. According to Yuan and Ng [22] wind speed less than $0.3 \mathrm{~m} / \mathrm{s}$ is considered to be stagnant pedestrian level natural ventilation within a street canyon implying insufficient removal of heat which tends to build up over time. Heat dissipated from urban surfaces (windows, ground, etc.) adds on to the rise in the ambient temperature due to lower convective heat exchanges because of limited air movement. Hence higher temperature intensity was experienced in these areas leading to hotspots. Due to the presence of these hotspots, nearby air temperature interacts with the higher temperature of the hotspots. Zeroth law of thermodynamics states that higher 
(a)

(b)

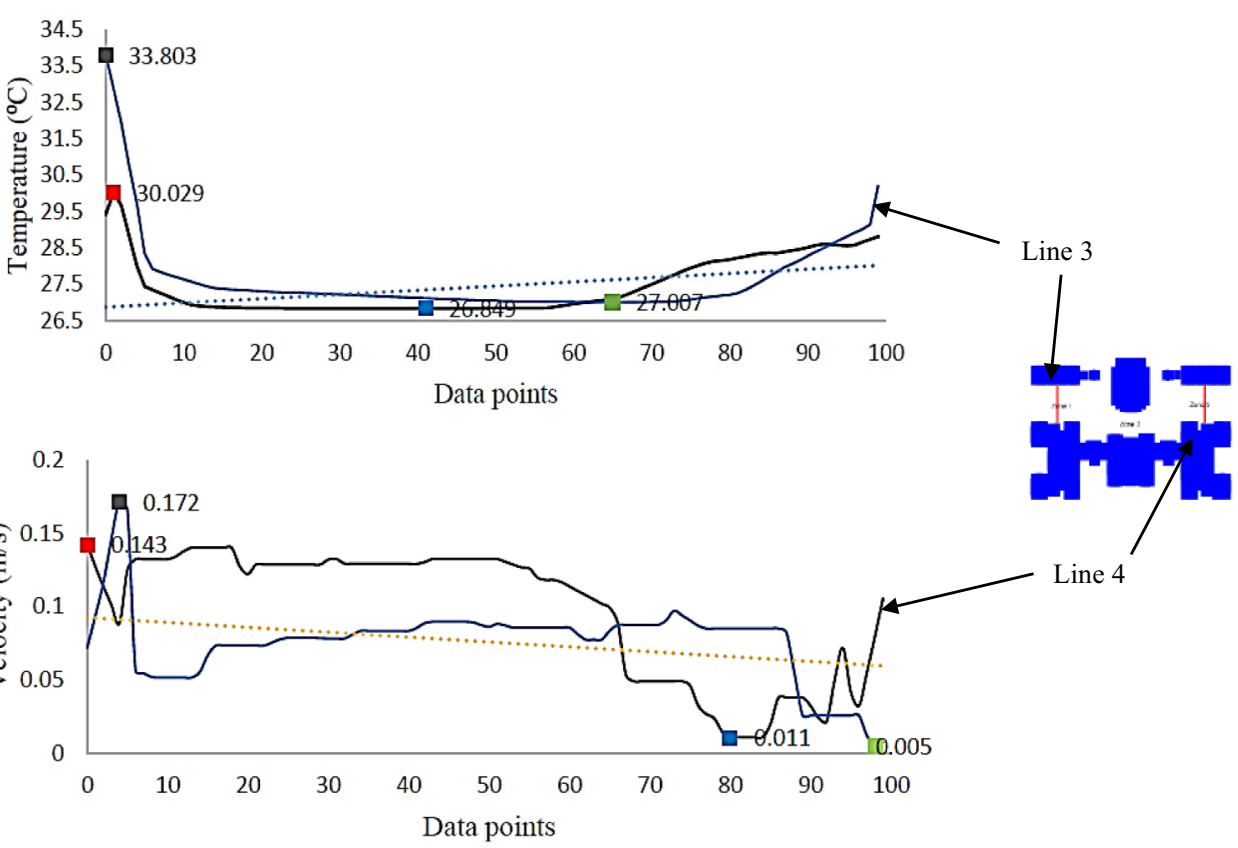

Fig. 12. Instantaneous variations in radial (a) temperature, (b) velocity parameters.

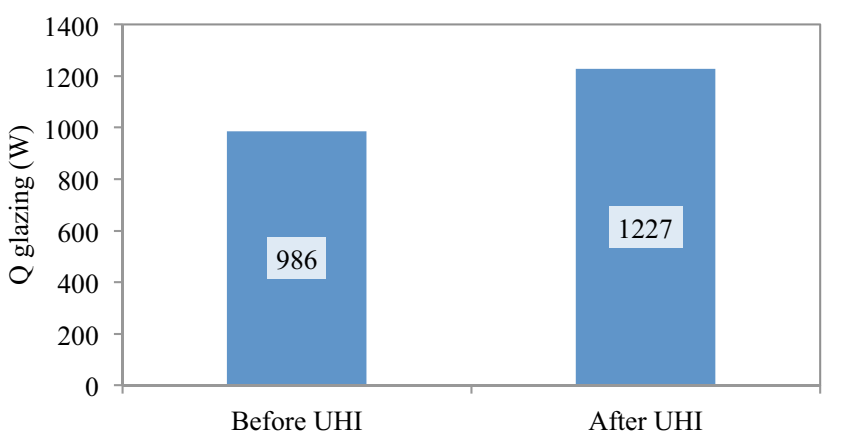

Fig. 13. Sensible cooling load due to glazing before and after the heat island effect.

temperature from a fluid or object transfers to a body or a fluid with lower temperature in order to attain thermal equilibrium [23], therefore relatively lower ambient air temperature $\left(27^{\circ} \mathrm{C}\right)$ undergoes a rise through heat exchanges with hotspots $\left(29.7^{\circ} \mathrm{C}\right)$ thereby spreading across the physical domain. The relationship between temperature and wind velocity observed concludes that the temperature is inversely proportional to air velocity.

Zone 2 experienced a temperature rise of $0.74^{\circ} \mathrm{C}\left(27.7^{\circ} \mathrm{C}\right)$ as seen from Figure 6. According Voogt [24], heat islands are caused when the temperature rise is more than $1{ }^{\circ} \mathrm{C}$ than the actual ambient temperature. Figure 7 shows relatively higher air velocity $(0.32-0.4 \mathrm{~m} / \mathrm{s})$ that helps to flush out the heat. Although the presence of glazing would allow for increased temperature due to increased convective heat exchange from relatively higher glazing surface temperature in zone 2 , the narrow corridor and staggered phase 2 central building allows for an increased streamline effect that helps to increase air velocity allowing heat removal. To support this phenomenon, evidence from literature suggests that increase in the wind velocity increases the convective heat transfer with the building façade and heat removal [6]. As a result, zone 2 and inlet location displayed lower surface temperature indicating negligible heat transfer.

\subsection{Relationship between building geometry and wind flow speed/pattern}

As observed from the findings, the wind exerted higher pressure on the windward side of the building (zone 1) causing the wind flow to move towards the leeward side (zone 3 ). The initial speed of the prevailing wind was measured as $0.4 \mathrm{~m} / \mathrm{s}$, however, upon impact, the wind sheared laterally around the building causing the speed to reduce around the building symmetry due to frictional drag from surface roughness of the building. The wind speed was found to increase in the outdoor void due to the acceleration caused by the wind deflection upon hitting the building. Thus, maximum air velocity was found to be in the zone 1 region reaching up to $0.64 \mathrm{~m} / \mathrm{s}$.

HWUDC being a symmetrical building with continuous flushed and recessed walls has spaces through which wind does not circulate resulting in low or no air movement in these areas. As the prevailing wind is parallel to the long face of the building, the wind passes straight past without circulating in the recessed regions causing the heat to retain within the space. In addition, large amount of glazing located within a small enclosed area added to the rise of temperature by $2.7^{\circ} \mathrm{C}$, consequently becoming a dominant factor for the occurrence of hotspots.

\subsection{Consequences of the increased temperature on the cooling demand}

The thermal profile in Figures 6 and 8 displayed higher temperatures adjacent to glazing. Maximum temperature was found to be in zone 2 of about $35.08^{\circ} \mathrm{C}$ being $23 \%$ higher than the ambient temperature. The increased glazing 
temperature affects the resulting air temperature adjacent to these glazed façades. This temperature rise caused the sensible cooling load through glazing to increase by $19.61 \%$. Following the heat island effect, the ambient temperature increased by $4.32 \%$. As the sensible cooling load depends on external temperature any change in the external temperature would lead to changes in the sensible cooling loads through glazing. Thus the cooling loads were observed to increase from $986 \mathrm{~W}$ to $1227 \mathrm{~W}$.

From a study conducted in Greece it could be seen that as the mean steady state heat island exceeds $10^{\circ} \mathrm{C}$, the cooling load on the buildings doubled [25].

According to the EPA [26] for every $0.6^{\circ} \mathrm{C}$ of rise in the air temperature, electrical consumption due to increased cooling demand increases by $1.5 \%$ to $2 \%$. Moreover, variations in the external ambient air temperature lead to significant consequences on thermal performance of the building [13]. Al-Sallal [27] estimated that due to UAE's harsh climatic conditions, $60 \%$ of the building's energy consumption is accounted by high cooling demands. Thus even a small degree rise in air temperature could have a catastrophic rise on the total energy demand of a building. Hence HIs are one of the phenomenon that negatively affect the local micro climate leading to increase in the space cooling demand which in turn increases carbon emissions due to increased peak electricity load from air-conditioning.

\section{Conclusion}

This study analysed the wind flow and temperature distribution for the assessment of steady state temperature and flow profile around buildings in the UAE. The numerical investigation was carried out using CFD, the findings of which were validated using far-field experimentation. The findings indicated those specific locations in the zone 1 and 3 region experienced $9.1 \%$ increase in the ambient temperature which caused a temperature increase of $2.7^{\circ} \mathrm{C}$ leading to the formation of hotspots in these regions. The findings determined that wind flow pattern and speed was one of the major factors in the formation of higher temperatures along with the building geometry that altered the wind velocity and high convective heat exchanges from glazing façade with relatively high surface temperature.

Zones with high air temperatures had relatively lower velocities in the corresponding regions. Thus it was concluded that the air temperature is inversely proportional to the wind velocity around the campus. Highest maximum temperature of $28.22^{\circ} \mathrm{C}$ was found adjacent to the window near zone 1 due to $4.32 \%$ increase in the adjacent surface temperature. The temperature rise caused the sensible load to increase by $19.61 \%$ leading to adverse effect on the electricity demand. Based on the extensive analysis conducted in this work, the study has established potential for assessing and quantifying the consequences of steady state heat island in the context of the sensible cooling requirements. The current study provides scope to be furthered by assessing the steady state heat island phenomenon in terms of solar radiation which is one of the major factors for the high temperatures in UAE.

\section{References}

1. EPA, Heat island effect [online] (2014), available: http:// www.epa.gov/heatisland/ (accessed on: 2014/15/09]

2. T.R. Oke, The energetic basis of urban heat island, J. R. Meteorol. Soc. 108, 1 (1982)

3. B.Y. Tam, W.A. Gough, T. Mohsin, The impact of urbanization and the urban heat isl5and effect on day to day temperature variation, Urban Clim. 12, 1 (2014)

4. P. Rajagopalan, K.C. Lim, E. Jamei, Urban heat island and wind flow characteristics of a tropical city, Solar Energy 107, 159 (2014)

5. Climate Research Group, Urban Heat Island Research Project [online] (2012), available: http://www.uta.edu/faculty/awin guth/uhi/dfw_uhi.html (accessed on: 2014/04/10)

6. J. Allegrini, V. Kämpf, J. Dorer, J. Carmeliet, Modelling the urban microclimate and its influence on building energy demands of an urban neighbourhood, in CISBAT 2013 (2013)

7. M. Brown, Urban parameterizations for mesoscale meteorological models [online] (2014), available: http://www. researchgate.net/publication/258703466_Urban_parame terizations for mesoscale meteorological models (accessed on: 2014/10/10)

8. B. Fisher, J. Kukkonen, M. Piringer, M.W. Rotach, M. Schatzmann, Meteorological applied to urban air pollution problems: concepts from COST 715, Atmos. Chem. Phys. Discuss. 5, 7903 (2005)

9. N. Abid, I. Kolo, I. Janajreh, Computational fluid dynamics study on wind, solar effect and pollutant dispersion in Masdar City, in 19th Australasian Fluid Mechanics Conference Melbourne, 2014 (2014)

10. K. Cho, T. Kono, Y. Ashie, Large-scale CFD simulation of heat island phenomenon and countermeasures in Tokyo, in Annual Report of the Earth Simulator Center, April 2007- March 2008 (2008)

11. D. Taleb, B. Abu-Hijleh, Urban heat islands: potential effect of organic and structured urban configurations on temperature variations in Dubai, UAE, Renew. Energy 50, 747 (2012)

12. R. Priyadarshini, W.N. Hien, C.K.W. David, Microclimatic modeling of the urban thermal environment of Singapore to mitigate urban heat island, Solar Energy 82, 727 (2008)

13. H. Radhi, On the effect of global warming and the UAE built environment, global warming. Stuart Arthur Harris [online] (2010), available: http://www.intechopen.com/books/glob al-warming/on-the-effect-of-global-warming-and-the-uaebuiltenvironment (accessed on: 2015/29/03)

14. Y. Toparlar, B. Blocken, P. Vos, G.J.F. van Heijst, W.D. Janssen, T. van Hooff, H. Montazeri, H.J.P. Timmermans, CFD simulation and validation of urban microclimate: a case study for Bergpolder Zuid, Rotterdam, Build. Environ. 83, 1 (2014)

15. X. Song, J. Liu, CFD simulation of micro-climate in waterfront (2013), France [online], available: http://www. ibpsa.org/proceedings/BS2013/p 1066.pdf (accessed on: 2014/15/12)

16. H.N. Chaudhry, A study on optimising heat pipe geometrical parameters for sustainable passive cooling within the built environment, Appl. Therm. Eng. 93, 486 (2016)

17. S. Wilkinson, S. Hanna, L. Hesselgren, V. Mueller, Inductive aerodynamics' computation and performance, in Proceedings of the 31st eCAADe Conference 2013 (2013), Vol. 2, pp. 29-48 [online] 
18. CIBSE Guide A, Environmental design (The Chartered Institution of Building Services Engineers, London, 2006), 7th edition, p. 15

19. M. Shengwei, Top 5 misunderstandings on (good) mesh [online] (2011), available: http://caewatch.com/top-5-mis understandings-on-good-mesh/ (accessed on: 2015/05/02)

20. P. Dandgawal, Estimate the natural environment conditions with CFD [online] (2013), available: http://www.cctech.co. in/live/2013/06/19/estimate-the-natural-environment-con ditions-with-cfd/ (accessed on: 2015/05/02)

21. S. Houdal, N. Zemmouri, A. Hasseine, R. Athmani, R. Belarbi, A CFD model for simulating urban flow in complex morphological street network, TOJSAT: Online J. Sci. Technol. 2, 1 (2012)

22. C. Yuan, E. Ng, Building porosity for better urban ventilation in high-density cities: a computational parametric study, Build. Environ. 50, 176 (2011)

23. Y. Çengel, M. Boles, Thermodynamics: an engineering approach (McGraw-Hill, USA, 2007)
24. J.A. Voogt, Urban Heat Islands: hotter cities [online] (2004), available: http://www.actionbioscience.org/environment/ voogt.html (accessed on: 2014/04/10)

25. M. Santamouris, N. Papanikolaou, I. Livada, I. Koronakis, C. Georgakis, A. Argiriou, D.N. Assimakopoulos, On the impact of urban climate on the energy consumption of buildings, Sol. Energy 70, 201 (2001)

26. EPA, Heat island effect [online] (2013), available: http:// www.epa.gov/heatislands/impacts/index.htm (accessed on: $2015 / 29 / 03)$

27. K.A. Al-Sallal, Tower buildings in Dubai - are they sustainable? in CTBUH conference, Seoul, 2004 [online] (2004), available: http://ctbuh.org/Portals/0/Repository/ Al-Sallal_2004_TowerBuildingsinDubai.b82e3a40-df3441f1-8744-48045978a6fd.pdf (accessed on: 2015/01/04)

28. K. Setaih, N. Hamza, M.A. Mohammed, S. Dudek, T. Townshend, CFD modeling as a tool for assessing outdoor thermal comfort conditions in urban settings in hot arid climates, J. Inf. Technol. Constr. 19, 248 (2014)

Cite this article as: S.F. Fatima and H.N. Chaudhry: Steady-state CFD modelling and experimental analysis of the local microclimate in Dubai (UAE). Sust. Build. 2, 5 (2017). 